\title{
Comparison of thermal and electrical tomography in medicine
}

\author{
by A. Nowakowski
}

Gdansk University of Technology, Department of Biomedical Engineering

\begin{abstract}
Diagnostic modalities - Thermal Tomography (TT) and Electroimpedance Tomography (EIT) - both new in clinical applications, are challenging for acceptance in medical diagnostics. Basic thermal and electroimpedance tissue properties are compared. Diagnostic importance of both modalities is underlined showing common value in many applications. Advantages and week points are discussed. Basic medical applications, especially the research results of the Department of Biomedical Engineering Gdansk University of Technology (TUG) are shown.
\end{abstract}

\section{Introduction}

Tomography is known in medical diagnostics as the most advanced technology for visualisation of tested object internal structures. X-rays - CT (Computed Tomography), NMR - MRI (Magnetic Resonance Imaging), ultrasound imaging, SPECT (Single-Photon Emission Computed Tomography), PET (Positron-Emission Tomography) are the modalities of established position in medical diagnostics [1]. There are three additional tomography modalities, still in a phase of development optical (OT), electroimpedance (EIT) and thermal (TT). We concentrate our notice on TT and EIT as both represent similar and complementary diagnostic importance. The aim of this presentation is discussion of potential applications of both modalities and analysis of limitations existing in medical diagnostics.

General concept of tomography requires collection of data received in so called projections; data from all projections form a scan. In the oldest CT, the tomography procedure requires irradiation of a tested object from different directions (projections), all possible projections giving one scan. Then, basing on realistic model of a tested object, a reconstruction procedure based on solving so called inverse problem allows visualisation of external structure of a tested object. In early systems the 2-D picture of internal organs was shown, nowadays more complex acquisition systems allow to visualise 3-D cases. More or less similar procedures are applied in TT and EIT. The main advantages of both technologies are fully safe investigation and relatively low cost of instrumentation. The goal of this paper is to compare TT and EIT in terms of validity for reliable medical diagnostics.

\section{Thermal \& electrical tissue properties}

To compare TT and EIT we should ask the question - is there any correlation between thermal and electrical properties of biological tissues? The problem of basic definition of figures of merit describing both domains may be omitted if normalised values of interesting parameters are regarded. Here we assume blood as the most important tissue, for comparison to other tissues, because it is the main medium important for transfer of fast metabolic changes, basic component of heat transfer and medium used for observation of mechanical transients in human body, too. 


\section{http://dx.doi.org/10.21611/qirt.2004.099}

Tab.1 shows approximate values of relative parameters: density, thermal conductivity, thermal effusivity and electrical conductivity. The ratios of a tissue parameter characteristic value to the reference blood parameter are given. One should remember that the values are of approximate character, as a big diversity of different parameter values for a living tissue exists. It is clearly seen that thermal properties do not differ importantly, therefore it would be difficult to use TT for discrimination of internal body structure. Much better situation is in electrical domain, where properties of different tissues are well differentiated. Additional factor limiting TT is the slow speed of thermal transients, what always should be taken into account.

Table 1. Relative (to blood) values of thermal and electrical parameters of different tissue (approximate values)

\begin{tabular}{|l|l|l|l|l|}
\hline Tissue & \multicolumn{1}{|c|}{$\begin{array}{c}\text { Relative } \\
\text { density } \\
\Delta / \Delta_{\mathrm{b}}\end{array}$} & $\begin{array}{c}\text { Thermal } \\
\text { conductivity } \\
\mathrm{k} / \mathrm{k}_{\mathrm{b}}\end{array}$ & $\begin{array}{c}\text { Thermal } \\
\text { effusivity } \\
\beta / \beta_{\mathrm{b}}\end{array}$ & \multicolumn{1}{|c|}{$\begin{array}{c}\text { Electrical } \\
\text { conductivity } \\
\sigma / \sigma_{\mathrm{b}}\end{array}$} \\
\hline Heart muscle & 1 & 1,08 & 1,05 & 0,375 \\
\hline $\begin{array}{l}\text { Skeletal muscle } \\
\text { transverse }\end{array}$ & 0,985 & 1 & 1 & 0,093 \\
\hline $\begin{array}{l}\text { Skeletal muscle } \\
\text { longitudinal }\end{array}$ & 0,985 & 1 & 1 & $0,5-1$ \\
\hline Brain & 0,976 & 1,10 & 1,05 & 0,26 \\
\hline Kidney & 0,990 & 1,04 & 1,025 & 0,405 \\
\hline Liver & 1 & 1,08 & 0,985 & $0,18-0,4$ \\
\hline Lungs & 0,990 & 0,8 & 0,8 & $0,06-0,14$ \\
\hline Fat & 0,86 & 0,44 & 0,53 & 0,05 \\
\hline Blood & 1060 & $\begin{array}{l}0,49 \\
{[\mathrm{~W} /\{(\mathrm{m})(\mathrm{K})\}]}\end{array}$ & $\begin{array}{l}1370 \\
{\left[\mathrm{~J} /\left(\mathrm{m}^{2} \mathrm{Ks}^{1 / 2}\right)\right]}\end{array}$ & $\begin{array}{l}6,710^{-3} \\
{[\mathrm{~S} / \mathrm{cm}]}\end{array}$ \\
\hline
\end{tabular}

\section{Thermal Tomography}

Thermographic Non Destructive Testing (TNDT) based on active dynamic thermography is under intensive development during the last 20 years [2]. The concept of material testing by active dynamic thermography is based on delivery of some energy to a specimen and observation of thermal transients as the response. This concept is also applied in thermal tomography (TT). Probably Vavilov $[3,4]$ was the first who proposed the term Thermal Tomography but he was dealing with TNDT of mechanical structures. The idea was to slice thermally a specimen in depth. In practice it is a "pseudo-tomography" as the proposed procedure is performed assuming only one-dimensional heat transfer. Analysis is based on the observation that the time of maximum thermal contrast is proportional to the square of the depth of a thermal defect. Somehow similar is the concept of "slicing" proposed in [5] and applied for breast cancer evaluation. The slices are evaluated basing on the shape of temperature distribution assuming that it fits to a simple thermal RC model. Probably the first in vivo experiments with active thermography have been performed 20 years ago in VUB [6]. Experiments with external excitation using microwave applicator have been very promising, but without any clinical follow up. Basing on more complicated multi-layer models medical TT applications are just under intensive development in 


\section{http://dx.doi.org/10.21611/qirt.2004.099}

our department. The first in vivo experiments and applications are in evaluation of the depth of skin burns, in cardiosurgery and even in breast cancer studies $[7,8,9,10,11]$.

We proposed a simplified description of parametric images basing on visualisation of thermal time constants, which values are correlated with internal structure of tested objects $[12,13,14,15]$. The next most important step was the attempt to form real tomographic visualisation of 3-D structures, solving real inverse problem. It solves the problem - find distribution of thermal conductivity inside the tested object. This attempt is fully successful in the case of skin burn evaluation, giving a powerful tool in hands of medical doctors allowing reliable quantitative evaluation of the burn depth $[9,10,16,17,18]$. Other applications are under intensive research $[8,11,19]$.

In TT the first step is determination of thermal properties of a tested object, necessary for development of its thermal equivalent model, to be applied for further data treatment. A typical procedure allowing the model parameters determination is shown in Fig.1. The forward problem is solved and assumed model parameters are modified to satisfy a chosen criterion for model and measurement data comparison. Very similar is the procedure in EIT, but electroimpedance data and models must be applied. The second step is organisation of an active dynamic thermography experiment and registration of thermal transients forced by external excitation.

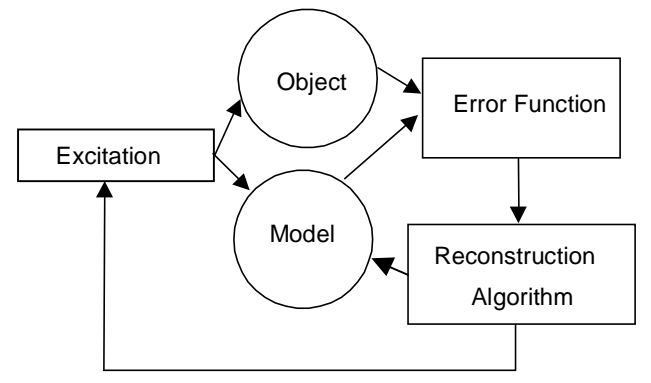

Fig.1 Determination of model parameters, based on comparison of measurement and simulation data, valid for all kind of tomography.

The next step requires advanced calculations to solve the inverse problem. The information of the correlation of the calculated figure of merit with a specific diagnostic feature is necessary to take a proper diagnostic decision based on the performed measurements. The decision function is directed to determine the internal thermal structure of the tested object basing on thermal transients at its surface. In this case a real inverse problem has to be solved. We perform this procedure using Matlab scripts [10,17]. As the result a multi-layer structure of different thermal properties may be reconstructed. To solve this problem additional assumptions, as number of layers, values of thermal properties or dimensions, are necessary because in general the problem is mathematically ill posed and non-linear.

\section{Electroimpedance Tomography}

There is a broad clinical use of electrical impedance measurements in functional studies of heart and cardiovascular system, in digestive system examination, in monitoring of respiratory system and in some other applications, also some clinical trials of EIT applications are related for several years, some concentrated on cancer detection (mammography) and brain examination. In 1999 Siemens offered the first commercially available El mammography visualisation system - TransScan. 


\section{http://dx.doi.org/10.21611/qirt.2004.099}

Practically it gives rather simple visualisation of 2D projections of breast tissue electrical properties and should not be called a tomograph. It has the approval of the US FDA. Recent developments of EIT are related to hardware solutions including multi-frequency measurements and to new reconstruction algorithms. The number of electrodes applied is rising and real 3D measurements and visualisation algorithms are implemented. Several research labs offer EIT systems, of 16/32 electrodes but reaching even 256 electrodes. Most of simple as well as more advanced systems are still operating only as laboratory prototypes. The extended information of the development in EIT may be found in [20,21].

Determination of tested object internal structure (conductivity distribution), basing on measurements of voltage and current distribution on its surface, is limited by the number of electrodes applied. In EIT the applied current flows in a way which is unpredictable and this is a serious problem resulting for the 2-D case in practical resolution of 16 electrode systems of about $12 \%$ of the image diameter. For full 3-D measurements using our 64-electrode system and 3-D reconstruction algorithm we have obtained volumetric resolution around $0,5 \%$, what is still far from the theoretical limit $[22,23,24]$. This is also far from clinical demands for cancer visualisation but is fully acceptable for functional visualisation. To deal with this problem accurate digital model of the object including models of applied voltage and current electrodes have to be constructed. Inaccuracy in geometry of a model has significant importance for the reconstruction, as the inverse problem is ill-posed and non-linear, too. The iterative and layer stripping algorithms allow to solve the non-linearity aspects. Still the accuracy of measurements is essential as even small errors in the boundary may lead to large errors of reconstructed conductivity distribution. There are two basic approaches to solve the reconstruction problem in EIT - reconstruction of absolute $(\mathrm{AR})$ and reconstruction of relative (RR) properties. $\mathrm{RR}$ algorithms are generally fast and of low computational cost but the results are rather rough, not precise and therefore are mainly applied to solve qualitative problems, as e.g. functioning of organs. AR methods are based on iterative procedures and are much more precise but the computational cost is also much higher than in the case of RR.

Situation is much more complicated in the case of organ visualisation if tissue properties are not differentiated by orders of magnitude. This is a typical case in the recognition of tumours, as in mammography. In this case the speed of operation is not so essential but the spatial resolution and differentiation of tissues just at the beginning of a malignant state is of the highest importance. The first question is what should be the measurement frequency for the highest ratio of electrical properties of healthy and malignant tissues. Here our ex vivo measurement data taken during the first 5 minutes after resection $[25,26,27]$ may be used to illustrate the problem. The measurements show the properties of tissues taken at the cancer centre, at the tubercle border (vicinity of the cancer) and of the healthy tissue, also resected due to security of the intervention. Evident is high difference of permittivity of the healthy and of the cancerous tissues, at higher frequencies, more than $1 \mathrm{MHz}$. The most important information for the use of EIT in mammography is, that the region of changed electrical tissue properties is much more expanse than the region detected by any of accessible visualisation techniques, including USG, MRI or X-ray mammography. It shows that EIT mammography may be valuable for early detection of breast cancer and for screening procedures, as a totally non-invasive method.

\section{Discussion and conclusions}

There are some similarities and problems in practical application of both technologies but also important differences, see e.g. [8]. TT is non-contact, assuring 
septic applications, while EIT requires direct electrical contact, although a new approach of inductive systems was reported. In this case the geometry resolution is poor, while in TT surface resolution depends on optical system and may be very high. Still, in both cases there are interfacing problems: in TT emissivity is influencing accuracy of data acquisition, similar is the problem of electrode-tissue impedance, affecting El measurements. Both modalities may be used for evaluation of tissues of affected vascularisation. Even thermal properties of different tissues may be not strong the heat transfer by blood is responsible for getting strong contrast in thermal images, so is the situation in EIT. Both modalities are relatively inexpensive.

TT allows reasonable accuracy of thermal properties reconstruction to the depth of $3-6 \mathrm{~mm}$ only. This may be increased by higher precision instrumentation application, but we are still on early state of development of this technology. Visualization of deeper structures is possible but the reconstruction data are of low quantitative value. The main applications are in burns diagnostics of superficial layers, skin transplants, evaluation of tissue quality, e.g. differentiation of wounded or dead regions, evaluation of vascularisation, etc. Technology is safe, septic and relatively easy in use, of high surface resolution but loosing this feature for deeper regions. EIT allows deeper penetration, gives similar visualization of regions with high blood perfusion. It may be applied in mammography, in evaluation of the state of organs, etc. The main disadvantage comparing to TT is low geometry resolution.

\section{Acknowledgements}

The author thanks his co-workers who participated in the research devoted to the development of TT as well as EIT in medicine and who produced the presented data. The work was supported by several KBN grants.

\section{REFERENCES}

[1] Bronzino J. ed. The Biomedical Engineering Handbook, CRC\&IEEE Press, 2000.

[2] Maldague X. P. V., Theory and Practice of Infrared Technology for Nondestructive Testing, J.Wiley \& Sons, Inc., New York, 2001.

[3] Vavilov V., Shirayev V., Thermal Tomograph - USSR Patent, 1.266.308, 1985.

[4] Vavilov V.P., 1D-2D-3D transition conditions in transient IR thermographic NDE, Seminar 64 - Quantitative IR Thermography - QIRT'2000, Reims, 74, 2000.

[5] Qi H., Kuruganti P.T., Liu Z., Early detection of breast cancer using thermal texture maps, IEEE Int. Symp. On Biomedical Imaging, Washington DC, $309-$ 312, 2002.

[6] Steenhaut O., Van Denhaute E., Cornelis J., Contrast enhancement in IRthermography by application of microwave irradiation applied to tumor detection, MECOMBE '86, 485-488, 1986.

[7] Nowakowski A., Kaczmarek M., Rumiński J., Hryciuk M., Renkielska A., Grudziński J., Siebert J., Jagielak D., Rogowski J., Roszak K., Stojek W., Medical applications of model based dynamic thermography, Proc. SPIE, v. 4360, 492-503, 2001.

[8] Nowakowski A, Kaczmarek M., Wtorek J., Siebert J., Jagielak D., Roszak K., Topolewicz J., Thermographic and electrical measurements for cardiac surgery inspection, Proc. of 23rd Annual International Conference IEEE EMBS, CDROM, Istanbul, 2001.

[9] Hryciuk M., Nowakowski A., Renkielska A., Multilayer thermal model of healthy and burned skin, Proc. 2nd European Medical and Biological Engineering Conference, EMBEC'02, v. 3, Pt. 2., pp.1614-1617, Vienna, 2002. 


\section{http://dx.doi.org/10.21611/qirt.2004.099}

[10] Nowakowski A., Kaczmarek M., Hryciuk M., Tomografia Termiczna, pp. 615 696, in Chmielewski L., Kulikowski J.L., Nowakowski A., Obrazowanie Biomedyczne, (in Polish) Biocybernetyka i Inżynieria Biomedyczna 2000, v. 8, Akademicka Oficyna Wydawnicza EXIT, Warszawa, 2003.

[11] Kaczmarek M., Nowakowski A., Analysis of Transient Thermal Processes for Improved Visualization of Breast Cancer Using IR Imaging, Proc. IEEE EMBC, Cancun, 1113-1116, 2003.

[12] Rumiński J., Nowakowski A., Kaczmarek M., Hryciuk M., "Model-based parametric images in dynamic thermography", Polish Journal of Medical Physics and Eng., 6(3, 159-164), 2000.

[13] Kaczmarek M., Nowakowski A., Renkielska A., Rating Burn Wounds by Dynamic Thermography, D. Balageas, J. Beaudoin, G. Busse. G. Carlomagno, ed., Quantitative InfraRed Thermography 5, 376 - 381, 2000.

[14] Rumiński J., Kaczmarek M., Nowakowski A., Medical Active Thermography - A New Image Reconstruction Method, Lecture Notes in Computer Science, LNCS 2124, Springer, Berlin-Heidelberg, 274-181, 2001.

[15] Nowakowski A., Kaczmarek M., Rumiński J., Synthetic Pictures In Thermographic Diagnostics, Proc. EMBS-BMES Conference; CD, Houston, 1131-1132, 2002.

[16] Kaczmarek M., Nowakowski A., Renkielska A., Grudziński J., Stojek W., Investigation of skin burns basing on active thermography, Proc. of 23rd Annual International Conference IEEE EMBS, CD-ROM, Istanbul, 4 p., 2001.

[17] Hryciuk M., Badanie struktury biologicznych obiektów warstwowych z wykorzystaniem pobudzenia cieplnego, (Ph.D. dissertation, in Polish) Politechnika Gdanska, 2003.

[18] Hryciuk M., Nowakowski A., Evaluation of thermal diffusivity variations in multilayered structures, Proc. 6 QIRT, Zagreb, 267-274, 2003.

[19] Kaczmarek M., Modelowanie właściwości tkanek żywych dla potrzeb termografii dynamicznej, (Ph.D. dissertation, in Polish) Politechnika Gdańska, 2003.

[20] Critical Reviews in Biomedical Engineering, Vol. 24, Issues 4-6, 1996.

[21] Proc. IX ICEBI, ed. Gersing E., ICPRBI, ISBN 3-88452-960-9, Heidelberg, 1995; Proc. X ICEBI, ed. Riu P., Office of UPC, ISBN: 84-7653-686-0, Barcelona, 1998; Proc. XI ICEBI, ed. Grimnes E., ISBN 82-91853-05-3, Oslo, 2001; Proc. XII ICEBI, ed. Nowakowski A., ISBN 83-917681-6-3, Gdansk, 2004.

[22] Nowakowski A., Wtorek J., Stelter J., Technical University of Gdańsk Electroimpedance mammograph., IX International Conference on Electrical BioImpedance, Heidelberg, 434- 437, 1995.

[23] Wtorek J., Stelter J., Nowakowski A., Impedance mammograph 3D phantom studies, Annals of New York Academy of Sciences, v. 873, 520 - 533, 1999

[24] Stelter J., Wtorek J., Nowakowski A., Factors influencing quality of imaging in 3D electroimpedance tomography, Medical \& Biological Engineering \& Computing, v. 37, suppl. 2, 158 - 159, 1999.

[25] Wtorek J., Polinski A., Stelter J., Nowakowski A., Cell for measurements of biological tissue complex conductivity, Technology and Health Care, 6, 177193, 1998.

[26] Stelter J., Wtorek J., Nowakowski A., Kopacz A., Jastrzębski T., Complex permittivity of breast tumor tissue, Proc. of $\mathrm{X}$ Intern. Conf. on Electrical BioImpedance, Barcelona, Spain, 59-62, 1998.

[27] Stelter J., Wtorek J., Poliński A., Nowakowski A., Bujnowski A., Comparison of sensing probe constructions for immitance spectroscopy of biological tissues, SPIE, Vol.3730, p. $189-198,1999$. 